\title{
Educação Clandestina: a proposição de um conceito
}

\section{Clandestine Education: a conceptual proposal}

\author{
Éder da Silva Silveira* \\ Diego Orgel Dal Bosco Almeida*
}

\begin{abstract}
RESUMO
O presente artigo busca refletir aspectos significativos de ordem teóricoconceitual sobre Educação Clandestina e as possíveis relações entre educação e clandestinidade. Partindo das contribuições associadas a um projeto de pesquisa desenvolvido no Brasil, o objetivo central é propor um conceito para Educação Clandestina, considerando as possibilidades de aplicação e os seus usos que emergiram dos diferentes enfoques e abordagens mobilizados em produções recentes sobre a temática. A partir de uma pesquisa de cunho qualitativo realizada sobre a educação de comunistas na clandestinidade, explora-se as potencialidades da denominação Educação Clandestina como um conceito/categoria operacional.
\end{abstract}

Palavras-chave: Educação. Clandestinidade. Educação Clandestina.

\begin{abstract}
The present article seeks to reflect on significant theoretical and conceptual aspects of clandestine education and the possible relationships between education and clandestinity. Based on the contributions associated with a research project developed in Brazil, the central objective is to propose a concept for Clandestine Education, considering the possibilities of application and its uses that have emerged from the different approaches mobilized in recent productions on the theme. Based on a qualitative
\end{abstract}

${ }^{*}$ Universidade de Santa Cruz do Sul. Santa Cruz do Sul, Rio Grande do Sul, Brasil. E-mail: eders@unisc.br - https://orcid.org./0000-0002-1242-2126 E-mail: diegoal@unisc.br - https:// orcid.org./0000-0001-5715-3591 
research carried out on education of communist in clandestinity, we explore the potentialities of the denomination Clandestine Education as an operational concept/category.

Keywords: Education. Clandestinity. Clandestine Education.

\section{Introdução}

Há cerca de cinco anos nosso grupo de pesquisa ${ }^{1}$ vem desenvolvendo um projeto sobre Educação Clandestina (SILVEIRA; MORETTI; PEREIRA, 2019a, 2019b). Inicialmente, a investigação recebeu auxílio da Fundação de Amparo à Pesquisa do Estado do Rio Grande do Sul (Fapergs/Brasil) e, depois, do Conselho Nacional de Desenvolvimento Científico e Tecnológico (CNPq/ Brasil), através do Programa Primeiros Projetos, cuja concessão e vigência envolveu o período de 2015 a 2019. A pesquisa, vinculada à subárea História da Educação, visava, dentre seus principais objetivos, explicar quais foram e como ocorriam as práticas de educação desenvolvidas por comunistas brasileiros no período em que estiveram na clandestinidade, sobretudo ao longo da segunda metade do século XX.

O projeto, intitulado Educação clandestina e traição: uma história da educação dos comunistas no Brasil da Guerra Fria, foi pautado na necessidade de compreensão das formas, mecanismos e funções da educação para os comunistas no contexto que interliga a década de 1950 ao período da ditadura militar brasileira (1964-1985). No entanto, permitiu também ampliar a reflexão sobre histórias e memórias de práticas educativas em diferentes regimes de clandestinidade, além de aspectos relacionados às múltiplas dimensões da clandestinidade na educação. Educação e clandestinidade foi o núcleo central da proposta de pesquisa. Durante sua execução, fomos compreendendo que a temática exigia uma intersecção teórica com o conceito de culturas políticas, particularmente sobre as culturas nas quais ocorriam as práticas educativas na ou para a clandestinidade. Assim, a clandestinidade, no caso dos comunistas brasileiros da segunda metade do século XX, foi um elemento constitutivo de sua cultura política. As fontes de pesquisa utilizadas variaram muito e, de certa forma, constituíram certo ineditismo no campo da História da Educação, uma vez que integravam inquéritos policiais e outros documentos produzidos pelos órgãos da repressão da ditadura militar brasileira.

1 Grupo de Pesquisa Currículo, Memórias e Narrativas em Educação. 
Para compreender as formas, mecanismos e funções da educação para os comunistas no recorte temporal analisado - que inclui os diferentes momentos de um contexto no qual comunistas brasileiros atuaram na clandestinidade - trabalhamos com inquéritos, dossiês, prontuários, relatórios e informes de operações da polícia política onde foram relatados, em detalhes, comportamentos e práticas daqueles que eram considerados "subversivos" (SILVEIRA; MORETTI, 2017; OLIVEIRA; SILVEIRA, 2017). Especificamente no que diz respeito às possibilidades de utilização desse tipo de fonte - que se refere a contextos repressivos -, trabalhamos também com autobiografias e memórias de viagens à União Soviética realizadas por comunistas brasileiros. A partir delas é que identificamos uma rede de educação clandestina, de dimensão internacional, que se organizava conforme os propósitos de organização do proletariado com vistas à uma revolução mundial.

Associada, em grande medida, ao contexto de diversificação de temas e fontes para a História da Educação, já identificado por Catani e Faria Filho (2002) e trabalhando com fontes oriundas de contextos marcados pela repressão política (BRAGGIO; FIUZA, 2013), a investigação nos exigiu buscar as possíveis intersecções entre três conceitos fundamentais para o tratamento de nossas fontes: educação, clandestinidade e culturas políticas.

Ao longo dos diferentes momentos do percurso da pesquisa, na medida em que houve um amadurecimento sobre as diferentes práticas de educação identificadas em nossas fontes, bem como sobre as suas possíveis relações com a cultura política comunista durante Guerra Fria, realizamos uma significativa extensão do debate sobre Educação Clandestina através da interlocução com pesquisadores e pesquisadoras de diferentes países. O resultado dessa interlocução, que evidenciou uma multiplicidade de abordagens entre educação e clandestinidade, se materializou em dois livros publicados, o primeiro intitulado "Educação e clandestinidade" (SILVEIRA; MORETTI; PEREIRA, 2019a) e o segundo "Educação e culturas políticas" (SILVEIRA; MORETTI; PEREIRA, 2019b), pela editora da Pontifícia Universidade Católica do Rio Grande do Sul (PUC-RS/Brasil). O conjunto dos dois volumes já publicados da obra Educação Clandestina ${ }^{2}$ permite observar que a denominação inicialmente proposta de Educação Clandestina, a partir da imposição dos desafios de uma pesquisa específica sobre a educação de comunistas brasileiros que viviam na clandestinidade durante o período da Guerra Fria, acabou extrapolando o período e o objeto de estudo, demonstrando que o termo pode servir como uma categoria

2 Os dois livros estão disponíveis para download gratuitamente no site da editora nos seguintes endereços: https://editora.pucrs.br/livro/1275/ e https://editora.pucrs.br/livro/1276/. 
analítica para diferentes áreas e aspectos de educação formal e não formal (e, educação escolarizada e não escolarizada) em diferentes temporalidades.

A questão nodal que articula a narrativa produzida neste artigo é qual concepção de Educação Clandestina emerge dos estudos e abordagens que se materializaram nas produções vinculadas ao nosso projeto de pesquisa e às nossas relações interinstitucionais durante a investigação? Partindo da compreensão de que a pesquisa em História da Educação trata-se de uma "moeda" de "dois lados", que combina tanto o rigor da pesquisa histórica quanto a reflexão sobre as realidades educativas (NÓVOA, 2011, p. 9), nos permitimos perguntar ainda: o que pode a Educação Clandestina? Quais as suas dimensões constitutivas e potencialidades? Considerando estas questões, o artigo que segue tem como objetivo propor algumas balizas de referência para o conceito de Educação Clandestina no sentido de pensar suas diferentes operacionalizações e contribuições para a área da educação.

\section{Educação Clandestina: o preâmbulo de um conceito}

Nossa pesquisa esteve ancorada no campo de estudos da História da Educação, como falamos anteriormente. Ela previa, desde o início, a análise de diferentes tipologias de fontes, desde documentos oficiais da polícia política brasileira da ditadura militar, passando por jornais comunistas até narrativas de memórias e autobiografias de militantes e de ex-militantes que viveram na clandestinidade no Brasil e no exterior. Cada tipo de fonte exigiu-nos implementar balizas teórico-metodológicas específicas e, também, um constante movimento de retorno às nossas concepções sobre educação e clandestinidade. Na prática, cada fonte ou recorte temático assumido durante a pesquisa provocava um retorno diferente às concepções iniciais, promovendo uma constante atualização conceitual, fruto das práxis realizadas no percurso de investigação. A ideia era articular os conceitos de educação e clandestinidade associando-os, primeiramente, àquilo que, de uma perspectiva mais teórico-prática encontramos na combinação das principais referências histórico-educacionais e da literatura do campo educacional. Perguntando-nos sobre educação, clandestinidade e Educação Clandestina, percebíamos que as reflexões levavam, também, a uma inflexão do conceito de culturas políticas.

A primeira pergunta foi "O que é educação". Responder a essa indagação, ainda que não de modo definitivo, foi um dos nossos primeiros esforços. Preocupação que, sem dúvida, nos acompanhou durante o percurso da 
pesquisa, principalmente em função da caracterização de "clandestina" que acompanhava "educação". Daí nossa outra pergunta: quando estamos falando de clandestinidade ou clandestino, o que isso significa, afinal? Consideramos que as duas nomenclaturas carregam um caráter polissêmico.

Por certo, não há "uma forma única ou um único modelo de educação" e a "escola não é o único lugar onde ela acontece e talvez nem seja o melhor". O "ensino escolar não é a sua única prática e o professor profissional não é o seu único praticante" (BRANDÃO, 2002, p. 9). Como um "poliedro de muitas faces" a educação pode expressar significados muitos distintos e variados (CABANAS, 2002, p. 52). Assim, partimos das seguintes premissas: I) que a educação é uma prática social que atua em duas direções principais: "no desenvolvimento de suas forças produtivas e no desenvolvimento de seus valores culturais" (BRANDÃO, 2002, p. 75); II) que "a educação sempre expressa uma doutrina pedagógica, a qual, implícita ou explicitamente, se baseia em uma filosofia de vida, e em uma concepção de homem (sic) e de sociedade"; III) que "numa realidade social concreta o processo educacional se dá através de instituições específicas que se tornam porta-vozes dessa doutrina" (FREITAG, 1986, p. 13).

Quanto à clandestinidade ou à condição de clandestino, também nos vimos diante de muitas possibilidades e discussões no âmbito de nosso projeto. Se por meio de uma consulta rápida a dicionários gerais encontramos acepções como "algo feito às escondidas", "aquilo que não apresenta condições de publicidade/ visibilidade prescritas em lei", que está "oculto", "ilícito", "escondido", "ilegal", foi necessário ir além desses significados mais gerais, considerando as contribuições encontradas na historiografia.

O historiador Mozart Lacerda Filho (2011) desenvolveu algumas considerações importantes nos seus estudos sobre a experiência da clandestinidade de ex-militantes de esquerda na ditadura militar brasileira: refletir a clandestinidade exige "uma interpretação polifônica", onde é preciso, inclusive, atender a "conceitos psicanalíticos" como "trauma, sublimação, resistência". Para esse mesmo historiador, clandestinidade pode representar, também, além da ilegalidade e invisibilidade, "projeto e imposição" (LACERDA FILHO, 2011, p. 9). Isso quer dizer que ser clandestino ou viver em situação de clandestinidade não representava "uma ruptura completa com a sociedade". Configurava-se, muito mais, como um "isolamento relativo", isto é, "uma situação onde duas condições antagônicas convivem simultaneamente: a visibilidade e a invisibilidade" (LACERDA FILHO, 2011, p. 29).

Outra contribuição significativa produzida no âmbito historiográfico no Brasil foi o estudo de Carolina Scarpelli (2009) sobre as marcas da clandestinidade em memórias da ditadura militar brasileira. Como buscou asseverar em sua pesquisa, "a clandestinidade interferiu e ainda interfere na subjetividade 
dos indivíduos que a vivenciaram". Assim, a experiência da clandestinidade "é muito heterogênea, vivida em função de uma série de singularidades, que vão desde traços de personalidade de cada indivíduo até às circunstâncias específicas da época" (SCARPELLI, 2009, p. 9). Portanto, pesquisar sobre ou a partir da clandestinidade, conforme as observações da historiadora Carolina Scarpelli (2009), contribui para inserir os múltiplos sujeitos de uma memória social, desvelando e problematizando os silêncios e os esquecimentos que a constituem.

A clandestinidade, embora inicialmente ligada à ilegalidade imposta aos partidos comunistas brasileiros, não poderia, tão somente, ser restringida apenas a essa noção. Em nosso entendimento, o conceito de clandestinidade está relacionado às necessidades de experiências individuais e coletivas que se vinculavam à partilha de identidades de grupo e à busca por projetos coletivos de futuro onde a própria educação comunista se colocava, então, não apenas como resistência, mas como projeto e vetor de mobilização e produção de sentido da própria cultura política.

O conceito de cultura política, central para se compreender as articulações entre educação e clandestinidade e a própria conceituação de Educação Clandestina, trata-se de um conceito multidisciplinar. Para os antropólogos Leandro Piquet Carneiro e Karina Kuschnir (1999), o conceito de cultura política aparece combinado a campos de estudos diversos, dentre os quais, Antropologia, Psicologia, Sociologia e História. O conceito apareceu, primeiramente, nos Estados Unidos. Gabriel Almond e Sidney Verba em um livro chamado "The Civic Culture" (1963) foram os primeiros autores que se utilizaram do conceito para estudos mais sistemáticos. Inicialmente, pode-se dizer que a conceituação se associou ao modelo culturalista norteamericano, cujo "objetivo" principal seria o "de estabelecer as inter-relações entre cultura e estrutura política, assim como suas avaliações da cultura política latino-americana"3. Em suma, um dos modelos de interpretação era a pretensa superioridade dos Estados Unidos e de sua cultura cívica em relação a outras. Essa leitura, algumas décadas depois, sofreu muitas críticas vindas, sobretudo, da ciência política. Apesar disso, em síntese, é possível afirmar que os estudos sobre cultura política: "rejeitam as explicações derivadas das teorias da escolha racional para os fenômenos políticos, privilegiando a esfera dos valores e da

3 Almond e Verba (1963) inspiraram-se em diversas áreas do conhecimento para o estudo daquelas que seriam as dimensões subjetivas da política. Sua principal influência foi um grupo de antropólogos que buscava compreender a cultura relacionada ao "caráter nacional". Esse grupo passaria a ser conhecido posteriormente como a Escola de Cultura e Personalidade que se desenvolveu, sobretudo, depois da Primeira Guerra Mundial. Sobre isso ver especificamente: Kuschnir e Carneiro (1999). 
percepção e avaliação subjetivados pelos indivíduos a respeito dos fenômenos". Consideram, igualmente, que cada indivíduo, quando participa de diferentes "tipos de instituição (família, classe, associação, partidos políticos, sistema educacional etc.), estaria exposto a distintas formas de socialização que podem ser congruentes ou não entre si” (CARNEIRO; KUSCHNIR, 1999, p. 229-242).

Os historiadores se apropriaram do conceito de cultura política ainda na década de 1960. Bernard Bailyn, em seu livro "As origens ideológicas da Revolução Americana" (1967), procurou defender a tese de que "uma cultura política anglo-americana" teria sido a raiz da rebeldia política dos colonos que "construíram a nova nação" (MOTTA, 2014, p. 17). Foi somente nos anos 1980-1990, no entanto, que historiadores franceses tomariam as discussões do conceito de cultura política, não sem antes exercerem a crítica ao modelo culturalista norte-americano em, pelo menos, dois aspectos: rejeitaram as explicações sobre qualquer ideia de superioridade democrática entre os países, especialmente dos Estados Unidos e da Europa; consideraram que uma ideia de "perspectiva nacional" era excessivamente "generalista ao atribuir a todo um povo as características de uma mesma cultura política" (MOTTA, 2014, p. 20). Exemplo desse trabalho de apreensão específica do conceito de cultura política pode ser encontrado nas considerações de Serge Bersntein, em "A cultura política”, no livro organizado por Jean François Sirinelli e Jean Pierre Rioux (1988). No Brasil, que foi influenciado pela historiografia francesa, o conceito de cultura política tem se mostrado muito fértil para pensar contextos políticos sob o ponto de vista da "força dos sentimentos [...], fidelidade a tradições [...] e a adesão a valores [...]" (MOTTA, 2014, p. 29). Como se pode notar, ainda que tenham se estabelecido críticas ao modelo culturalista, a concepção da existência de uma dimensão subjetiva da política tem sido uma tônica permanente. Para os fins que nos propomos no percurso de nossas investigações, consideramos o conceito de cultura política de modo amplo e o de cultura política comunista de maneira particular.

Ao considerar as culturas políticas, leva-se em conta que há vetores sociais que influenciam na reprodução de práticas, ações e valores que são compartilhados por um grupo específico e que o constitui enquanto grupo. As culturas políticas, além disso, não podem ser simplesmente encerradas nas organizações partidárias. Cultura política é um conceito polissêmico, mas pode ser compreendido como "conjunto de valores, tradições, práticas e representações políticas" que "partilhado por determinado grupo humano, expressando identidade coletiva e fornecendo leituras comuns de passado" também inspira "projetos políticos direcionados ao futuro" (MOTTA, 2013, p. 17-18). 
Pensar a interação dos conceitos de educação, clandestinidade e culturas políticas tornou-se significativo para compreender os sentidos das práticas de educação entre os comunistas que viveram na clandestinidade. Ou seja, sua identidade de grupo não se dava simplesmente pelo fato de os partidos comunistas estarem na ilegalidade. Se a ilegalidade institucional foi um fato desencadeador, as experiências dessa ilegalidade se converteram na clandestinidade enquanto característica marcante da trajetória de homens e mulheres que, ao longo do século XX, aderiram ao projeto e aos ideais comunistas. Foi, então, dessa situação que surgiram as práticas de educação que denominamos de clandestinas, porque elas são tanto o produto quanto a sustentação que constituiu, em grande medida, a cultura política comunista e a educação comunista na e para a clandestinidade.

Em nosso projeto, para que fosse possível pensar a educação comunista no campo de estudos da História da Educação, foi necessário compreendê-la, incialmente, enquanto educação não formal ou não escolar.

Há semelhanças nas considerações dos pesquisadores e pesquisadoras a respeito do que seja a educação não formal. Trata-se de uma educação que se realizaria "fora dos espaços escolares" e que "tem por finalidade desenvolver o ensino-aprendizagem de forma pouco explorada pela educação formal" (ALMEIDA, 2014, p. 4). A par dessa visão mais genérica em torno da ideia de uma "modalidade de educação", outros pesquisadores e pesquisadoras têm reconhecido que os estudos sobre educação não formal são ainda um campo em desenvolvimento. Maria da Glória Gohn (2006), por exemplo, acredita que se trata de "um campo de conhecimento em construção". Segundo o que diz a pesquisadora, a educação não formal aparece ligada a aspectos que, em geral, associam-se às dimensões da educação vinculada às "ações coletivas" e "organizações comunitárias". Um tipo de educação voltada à ideia de uma "pedagogia social", à "solução de problemas coletivos" e através da qual os grupos poderiam obter "uma leitura de mundo".

De fato, em relação à dimensão coletiva e social há muitas semelhanças entre a educação comunista e a educação não formal. A educação comunista, pela perspectiva da cultura política comunista, também se constitui a partir de um conjunto de elementos partilhados que expressam "identidade coletiva" (MOTTA, 2013, p. 17). No entanto, se concebermos a educação, em seu sentido amplo, enquanto "prática social" (BRANDÃO, 2002, p. 75) uma dimensão coletiva ou mesmo social é condição própria do conceito de educação. Assim, não sendo uma característica distintiva da educação não formal, não poderia sê-lo no conceito de Educação Clandestina. Embora tenhamos indicado que se tratava de uma educação não formal, fomos, no percurso da pesquisa, entrevendo outros elementos, aspectos e características que ultrapassavam essa conceituação. Educação Clandestina, apesar de possuir traços de educação não formal, integrava outros pontos bastante específicos. 
Se a educação comunista estava mais ligada aos elementos culturais vinculados ao comunismo, é possível afirmar que a condição de clandestinidade lhe conferia mais um elemento de identificação coletiva, um valor, um sentimento comum a ser partilhado que impunha cerceamento, mas que mobilizava um tipo de organização determinado, menos em função de uma modalidade de educação e mais em função de certas práticas que se inseriam em uma cultura política específica, a cultura política comunista. Assim, pode-se afirmar, a força da Educação Clandestina dos comunistas não estava no fato de ser considerada uma educação não formal. Sua força, suas características centrais residem mais nos aspectos vinculados às suas práticas e a função que cumpriam dentro de uma cultura política e que, no caso dos comunistas, ligava-se à condição de clandestinidade e se dava em função de um contexto de forte repressão que influenciava a cultura política comunista. As práticas de educação de seus partidários devem ser vistas, portanto, como um vetor de mobilização e de sustentação de sua cultura política. Ainda que a educação não formal possa se constituir a contrapelo daquilo que é considerado oficial em termos educacionais, ela não será, necessariamente, Educação Clandestina. Assim, considerando as temáticas e abordagens dos interlocutores que conosco participaram da obra Educação Clandestina, foi necessário reconhecer que a educação não formal é apenas um dos traços ou características da educação comunista e, também, que Educação Clandestina não diz respeito apenas a práticas de educação não-formal. Vejamos, a seguir, algumas análises de pesquisas que ajudam a compreender nossa proposição conceitual e suas dimensões constitutivas.

\section{Educação Clandestina: apontamentos conceituais}

O primeiro exemplo está na abordagem de Fernando Seffner (2019) em um texto de sua autoria intitulado Não há dois sem três: regimes de clandestinidade e processos educativos. O artigo, que integrou o volume 1 da obra "Educação Clandestina", colocou em interlocução os conceitos de educação e clandestinidade, inserindo a noção de "regimes de clandestinidade", que se baseia na premissa de que, em uma mesma educação, sujeitos podem viver diferentes regimes de clandestinidade. Assim, problematizando trajetórias educativas e escolares de homens e mulheres portadores do vírus HIV, Fernando Seffner salienta que "clandestino é, neste caso, alguém silencioso, que não consegue dialogar com os demais acerca daquela marca que o empurra para a clandestinidade" (SEFFNER, 2019, p. 38). 
As noções aplicadas à ideia de "regimes de clandestinidade" permitem pensar as relações com a temporalidade, admitindo a possibilidade da coexistência de experiências distintas de clandestinidade, que podem se tornar variáveis de acordo com as marcas de estigmas e discriminações que incidem na produção das realidades, dos sujeitos e suas subjetividades.

Fernando Seffner $(2019$, p. 38) ao se referir ao termo clandestino, observa que é comum pensar em "algo que se apresenta fora da legalidade, com propensão a ser feito 'às escondidas"'. No entanto, conforme ele mesmo destacou, "nem sempre aquilo que é clandestino é exatamente ilegítimo". Uma experiência de clandestinidade que apareceria associada à marcação do silêncio: “[...] alguém silencioso, que não consegue dialogar com os demais acerca da marca que o empurra para a clandestinidade [...] a diferença de que elas [as pessoas] são portadoras não se transforma em matéria de debate" (SEFFNER, 2019, p. 38). Ao problematizar a trajetória de estudantes e professores portadores de HIV, Seffner remete-se ao contexto atual brasileiro em que a AIDS voltou a ser "objeto de processos de estigma e discriminação" que ocorre por "derivação do pânico moral" vivido por significativa parte da "sociedade brasileira nos temas de gênero e sexualidade, dos quais são exemplos movimentos como a 'Escola sem Partido'4 e aqueles dos que lutam pela retirada de temas de gênero e sexualidade dos currículos", grupo que é denominado de "movimento contra a ideologia de gênero". Para esse pesquisador, alguns aspectos deveriam ser levados em consideração para saber sobre aquilo que ele denominou de "amplitude das áreas de clandestinidade":

Claro está que a amplitude maior ou menor das áreas de clandestinidade está relacionada ao regime político do país ou da região. Em um regime fortemente autoritário, uma ditadura, por exemplo, muitas atividades serão "empurradas" para a clandestinidade, bem como opiniões políticas, modos de expressão, filiação a ideias políticas, autores e livros, valores culturais, códigos morais e éticos, etc. Em um regime de amplo pluralismo democrático, podemos ter maior expressão pública da diversidade cultural, política, religiosa, moral, e a área de clandestinidade fica então reduzida.

4 Movimento ou Organização, Programa ou Projeto que ataca a liberdade de cátedra e se posiciona contra o ensino de questões de gênero e sexualidade nas escolas brasileiras. O Escola "Sem" Partido surgiu em 2004 por meio da iniciativa do então procurador do estado de São Paulo, Miguel Nagib. O projeto apareceu enquanto reação a uma suposta instrumentalização do ensino para fins políticos e ideológicos, o que representaria doutrinação e limitação da liberdade de aprender do estudante. Tornou-se projeto de lei apenas em 2014, no estado do Rio de Janeiro (PL 2974/2014) e, no mesmo ano, também foi apresentado na Câmara Municipal do Rio de Janeiro (PL 867/2014). 
Se o regime político é fortemente democrático e admite o pluralismo de ideias, posso discordar em público dos outros, tenho liberdade de expressão e não preciso viver na clandestinidade, minha diferença cultural é respeitada. Se o regime de governo é muito fechado e criminaliza a expressão de opiniões, termina por se gerar uma área de indivíduos e organizações clandestinas, e um conjunto de práticas, debates e valores que só podem se expressar na clandestinidade (SEFFNER, 2019, p. 39).

As dimensões de clandestino e de clandestinidade são trabalhadas por Seffner (2019) em relação ao "regime político" e a respectiva amplitude, maior ou menor, naquilo que diz respeito à democracia. Viver em regimes menos ou mais democráticos influencia diretamente a amplitude das áreas de clandestinidade. $\mathrm{O}$ atual governo, eleito em 2018, por exemplo, parece ter assumido as proposições do Escola sem Partido, "cuja ideologia se tornou pública por meio de sítio eletrônico e, ao mesmo tempo, fincava os pés no plano jurídico e lançava seus tentáculos para o interior das escolas em busca de supostos professores doutrinadores" (RAMOS, 2018, p. 7). Podemos, a partir da leitura das considerações de Seffner, inferir dois aspectos importantes que consideramos pertinentes para propor um conceito de Educação Clandestina.

O primeiro aspecto é a relação estabelecida entre a clandestinidade e o contexto político. Ainda que não necessariamente haja remissão específica ao conceito de cultura política, é possível pensar nessa categoria como possibilidade para compreender a "amplitude das áreas de clandestinidade", já que o próprio pesquisador trabalha com uma perspectiva de intensidade nas condições de ser clandestino e não precisamente de regime político. A diminuição ou a "amplitude das áreas de clandestinidade" aparece associada, neste sentido, a uma dimensão social e política, pois é referida através de valores, crenças, símbolos e representações de determinadas sociedades sobre gênero e sexualidade, assim como às estruturas diversas que constituem a experiência da desigualdade e da exclusão em contextos políticos específicos.

Trazendo a discussão para a educação escolar, como nos aponta Seffner (2019), é possível pensar que no contexto mais atual da sociedade brasileira os "marcadores de gênero e orientação sexual" têm implicado em considerável tensão nas relações entre indivíduos e grupos, o que se reflete na "cultura escolar", exigindo "modos adequados e respeitosos de ensino e convivência". A AIDS, enquanto doença que atinge sobretudo a população jovem, LGBT, pessoas "pobres em geral e com deficiência do acesso escolar, só pode ser enfrentada de modo adequado se não for relegada à zona de clandestinidade". As respostas que vem sendo dadas sobre este tema no Brasil estão se distanciando 
das "medidas de tratamento e prevenção com ampliação do acolhimento das diferenças [...], da diversidade dos modos de viver gênero e sexualidade, e mesmo dos modos de se relacionar com a doença". E esse distanciamento, possui "conexão com a diminuição do ambiente democrático brasileiro, situação vivida de modo mais intenso nos últimos anos" (SEFFNER, 2019, p. 53). Nessas zonas de clandestinidade nas quais são empurrados os soropositivos, há práticas de educação que ora se configuram como resistência, ora como projeto, numa complexa tensão entre visibilidade, invisibilidade e silêncio. A partir desse exemplo, elucidamos a dimensão política, uma das dimensões constitutivas da Educação Clandestina.

A dimensão política é importante na constituição do que foi denominado como Educação Clandestina, primeiro porque é vetor das intencionalidades que condicionam as possibilidades de ser do humano e da sociedade e, segundo, porque resulta de uma relação entre prática educativa e clandestinidade que se dá em culturas e regimes políticos específicos, nos quais a experiência da democracia é que vai condicionar a ampliação ou a mesmo a diminuição dos regimes de clandestinidade. Educação e clandestinidade, sob essa dimensão, se revelam menos como uma modalidade e mais como uma experiência que se constitui em um determinado contexto político e social e nas marcas que esse contexto provoca nos sujeitos individuais e coletivos. Esse contexto não necessariamente precisa ser compreendido a partir de um cenário de fechamento ou repressão de uma ditadura, por exemplo, mas da sobrevivência de características autoritárias que se fazem presentes mesmo em contextos democráticos. É possível estabelecer relações entre esses contextos e a cultura política. A "cultura escolar" poderá refletir aspectos do contexto e a escola poderá não se impor em relação a ele, ou seja, pode, como no caso examinado pelo autor, não se tornar um

local acolhedor para o debate de doenças de transmissão sexual, dos modos de viver a vida afetiva e sexual, a descoberta das possibilidades eróticas do corpo, todos esses processos que marcam a fase juvenil da vida (SEFFNER, 2019, p. 54).

O segundo exemplo, publicado no volume 2 da obra "Educação Clandestina”, é o artigo intitulado Educação comunista nas páginas do jornal A Classe Operária (1968-1970) (SILVEIRA et al., 2019c). Ao analisarem o jornal A Classe Operária, que foi periódico oficial dos dois principais partidos comunistas do Brasil da Guerra Fria, o Partido Comunista Brasileiro (PCB) 
e o Partido Comunista do Brasil (PCdoB), autor e autoras entenderam que o jornal foi um importante meio de educação naquela cultura política que, de diferentes formas, buscava educar e mobilizar politicamente a classe trabalhadora. Compreende-se que o jornal, como um órgão oficial do partido comunista, era valorizado entre os militantes e foi assumindo algumas funções na educação comunista. Novamente, em termos teóricos, a dimensão política e, em especial, o conceito de cultura política, foram mobilizados para analisar as práticas de Educação Clandestina assumidas ou materializadas no periódico pesquisado. É um texto importante porque demonstra que o jornal se constituía como um outro canal da educação comunista, além dos cursos de formação política e das práticas de militância. Nesse trabalho sobre o A Classe Operária, foi possível observar que os jornais comunistas se configuravam como uma forma de divulgação dos ideais que constituíam a cultura política comunista e como espaço e instrumento de educação, sobretudo nos momentos em que os comunistas se encontravam na clandestinidade.

Nos dois exemplos, Silveira et al. (2019c) mobilizaram formas diferentes de relação entre educação e clandestinidade. No primeiro, a interação se dá no espaço escolar, ou seja, demonstra que a clandestinidade na educação não aparece somente ligada à educação não-formal. Por outro lado, em ambos os estudos, a dimensão política do contexto estruturou e constituiu as relações estabelecidas pelos autores. No primeiro caso, a cultura e o regime político pouco ou menos democrático e inclusivo relegam o tema da AIDS e a existência dos soropositivos das escolas a regimes de clandestinidade ampliados devido a um contexto que favorece o silêncio e o tabu de temas como gênero e sexualidade. No segundo, a falta de democracia igualmente incide sobre a relação que foi estabelecida pelos comunistas com a clandestinidade. Relação marcada por práticas de educação voltadas para a segurança diante da iminente repressão, assim como para a unidade teórica e ideológica frente à ação e ao projeto de revolução. Assim, o jornal $A$ Classe Operária assumiu importante papel entre as alternativas de educação criadas na clandestinidade.

Voltando às coletâneas organizadas e publicadas por nosso grupo de pesquisa sob o título de Educação Clandestina, encontramos mais dois exemplos a partir dos quais se pode, ainda, apontar alguns destaques. No primeiro volume da coletânea, em capítulo intitulado Discriminação: a passageira clandestina da pedagogia, François Dubet afirma que,

por trás do funcionamento 'oficial' da escola e do reconhecimento do papel das desigualdades sociais na formação das desigualdades educacionais, a discriminação se apresenta como uma 'passageira clandestina da pedagogia' (DUBET, 2019, p. 17). 
Ao desenvolver o tema das discriminações clandestinas na sociedade e no sistema de ensino francês, Dubet (2019) destaca como as discriminações e a estigmatização operam de forma sutil nas práticas sociais, constituindo e, também, condicionando as experiências educativas.

Na mesma obra, Douglas Luís Weber e Camilo Darsie de Souza (2019), dois aspectos podem ser destacados: primeiro que, para esses autores, a dimensão clandestina ultrapassa a concepção jurídica da situação do migrante: "ser/estar clandestino não se refere aos vistos de permanência", mas como "os diferentes migrantes [...] produzem-se no contexto de 'vida clandestina' [...], por ocuparem a posição do outro, a posição do sujeito deslocado" (WEBER; DARSIE, 2010, p. 119-120); segundo que, ao se referirem à temática da clandestinidade dos sujeitos migrantes, partindo da exploração do conceito de espaço, procuram explicar que os "processos educacionais que atravessam os migrantes em função da passagem e/ou permanência em lugares diferentes daqueles que deixaram para trás" contribuem para enquadrá-los em uma "vida clandestina", isto é, em "uma posição de sujeito que os deixa permanentemente em situação de estranhamento no que se refere às populações autóctones" (WEBER; DARSIE, 2019, p. 126).

Cheron Zanini Moretti, em um capítulo sobre a experiência educativa descolonial dos e das zapatistas, aproximou os conceitos de educação e clandestinidade com o conceito de insurgência. Em seu estudo, a pesquisadora explica que, reivindicando-se como produto do processo histórico colonial, o Exército Zapatista de Libertação Nacional (EZLN) e sua base de apoio, campesina e indígena, não apenas criaram um Sistema Educativo Rebelde Autônomo Zapatista, mas também experienciaram tensões em seus territórios de resistências, além de outras lógicas de tempos e de lugares, como no diálogo horizontal entre conhecimentos e metodologias próprias ante a lógica hegemônica do sistema-mundo colonial-capitalista-patriarcal. A conclusão de Moretti (2019a) é a de que: "contra o desperdício da experiência, o zapatismo nos oferece uma pluralidade de alternativas contra-hegemônicas, a maior parte delas, gestadas na clandestinidade de seu exército e nas suas bases de apoio" (MORETTI, 2019a, p. 198). A autora, em produções a respeito do exílio vivido por Paulo Freire, tem observado a dimensão epistemológica e pedagógica da clandestinidade tanto em relação à obra do educador brasileiro como em relação à permanência clandestina de seu método de alfabetização durante a ditadura militar brasileira (MORETTI, 2010; MORETTI; PITANO; SCHULZ, 2019b).

Mas o que nos dizem esses exemplos quanto às dimensões conceituais daquilo que entendemos como Educação Clandestina? Em primeiro lugar, que a as práticas de Educação Clandestina podem ser gestadas na contingência das experiências de opressão vividas por sujeitos, espaços, pedagogias, currículos e territórios. Nessa perspectiva, vivem a clandestinidade enquanto prática social 
não apenas homens e mulheres, mas ideias, métodos, sistemas, símbolos e lugares. A dimensão formativa dessa experiência pode se dar pelas marcas da resistência, da exclusão ou da busca de projetos coletivos de futuro.

Assim, com base no que foi exposto até o momento, e com base nas reflexões e interlocuções que temos realizado e publicado no Brasil, podemos dizer que Educação Clandestina consiste em um conjunto de práticas sociais heterogêneas de formação, de resistência e de exclusão, resultantes e produtoras de culturas políticas menos ou mais abertas à democracia. Por estratégia ou imposição, são práticas marcadas pelo silêncio, por regimes de clandestinidade - distintos, complementares ou sobrepostos - definidos na dialética tensão entre liberdade e opressão, sendo, portanto, práticas constituídas a partir de experiências individuais e coletivas da (in) visibilidade, da (i)legalidade, e da (des)igualdade.

\section{Conclusão}

Propor algumas balizas de referência para o conceito de Educação Clandestina no sentido de pensar suas diferentes operacionalizações e contribuições foi o objetivo principal desse artigo. A rigor, trata-se de um conceito que abrange diferentes dimensões, tais como a política, a epistemológica, a cultural, a histórica e a pedagógica. Ainda que não tenhamos explorado todas as dimensões com o mesmo destaque, expressamos os principais elementos teóricos que deram sustentação à proposição conceitual apresentada, tão cara ao nosso grupo de pesquisa. Com isso, esperamos que os apontamentos realizados possam subsidiar reflexões no vasto campo de estudos educacionais. Como toda teoria, em geral, nasce de uma prática, optamos por contar sobre o andamento, sobre o nosso percurso de pesquisa, enfatizando os momentos em que os desafios de cunho teórico-conceitual se impuseram, impelindo-nos não só a procurar alternativas, mas debater, no próprio grupo e com nossos interlocutores, como e por quais caminhos, afinal, nós as procuraríamos. Por isso, na primeira parte deste artigo, buscamos situar a pesquisa desenvolvida nos últimos cinco anos em dois momentos: o primeiro, caracterizado como de reflexão acerca dos aspectos teórico-metodológicos relacionados à interação com as fontes de pesquisa; o segundo, configurado a partir de reflexões teóricoconceituais, ou seja, quando passamos a dialogar sobre os conceitos teóricos que poderiam assegurar a interação mais acertada em relação aos procedimentos de análise das fontes. Vimos que era impossível compreender adequadamente as 
práticas de educação comunista sem que se considerasse o conceito de culturas políticas de modo geral e o de cultura política comunista, em particular. Isto é, ao nos perguntarmos sobre as nossas fontes de pesquisa e sobre os conceitos de educação e clandestinidade, tivemos que entender o que significava ser clandestino e o que, afinal, as práticas de educação comunista guardavam de relação com a clandestinidade.

Já encaminhando a segunda parte, tratamos, mais precisamente, das dimensões conceituais da interação entre educação, clandestinidade e culturas políticas considerando o que se apresentava nas fontes principais de nossa pesquisa. Cabe destacar as diferenças que estabelecemos entre os conceitos de educação não-formal, educação comunista e Educação Clandestina. Embora a educação comunista, como uma das expressões daquilo que denominamos como Educação Clandestina, seja caracterizada por traços de educação não formal, não se pode afirmar que se encontre reduzida a essa noção. A educação não formal possui dimensões ligadas à coletividade, à ação coletiva, mas isso, por si só, não permite afirmar que a Educação Clandestina, por ser uma educação desenvolvida por meio de referências identitárias de grupo, possa ser conceituada apenas como educação-não formal. As práticas de educação de comunistas na clandestinidade se desenvolvem em um contexto bastante específico, de ilegalidade dos partidos comunistas, de fechamento da democracia e de repressão.

Como categoria de análise, a noção de Educação Clandestina surgiu da interação entre os conceitos de educação, clandestinidade e culturas políticas. Vimos que o conceito, diferentemente de estar relacionado apenas a um tipo ou modalidade de educação, sugere uma forte ligação com os contextos social e político. O contexto político que confere maior ou menor amplitude para os "regimes de clandestinidade" é uma de suas dimensões constitutivas. Esta dimensão permite explorar as diferentes estruturas e práticas que constituem a experiência da desigualdade e da exclusão em determinados contextos políticos e sua relação com a democracia.

Se considerarmos que diferentes experiências educativas ocorrem na clandestinidade ou em sua direção, podemos conceber a Educação clandestina como uma categoria ligada à experiência que se constitui em um determinado contexto político e social e nas marcas que esse contexto provoca nos sujeitos individuais e coletivos. Como vimos anteriormente, as práticas de Educação Clandestina podem ser gestadas na contingência das experiências de opressão vividas por sujeitos, espaços, pedagogias, currículos e territórios. Por isso, argumentamos que vivem a clandestinidade enquanto prática social não apenas homens e mulheres, mas ideias, métodos, sistemas, símbolos e lugares. A dimensão formativa dessa experiência pode se dar pelas marcas da resistência, da exclusão ou da busca de projetos coletivos de futuro. 
O caso da educação comunista se torna, como já dissemos, apenas uma das educações desenvolvidas na clandestinidade. Há outras possibilidades sendo exploradas, tanto no presente quanto no passado, tanto na educação formal quanto na não-formal. Em todas elas, a clandestinidade é menos uma situação legal e jurídica e mais um conjunto de experiências e práticas individuais e coletivas que são impostas por um contexto de cerceamento, mas que acabam estimulando a organização de grupos ou práticas sociais clandestinas.

Por fim, propor um conceito de Educação Clandestina a partir da identificação e análise de algumas de suas balizas de referência significou refletir sobre nosso percurso de pesquisa e os seus desafios. A partir dessa reflexão é que foi possível estabelecer os referenciais de cunho teóricoconceitual. Práticas sociais, formação, resistência e exclusão. Estratégia, imposição e silêncio. Regimes de clandestinidade que se inserem na dinâmica tensa e complexa de experiências individuais e coletivas que combinam invisibilidade e visibilidade; legalidade e ilegalidade, igualdade e desigualdade. Vale destacar, por fim, outra contribuição. Ao realizarmos a pesquisa, com diferentes enfoques sobre a Educação Clandestina, associada ao campo da História da Educação, tivemos um caráter de originalidade no Brasil, onde, geralmente, a História da Educação concede destaque a temas relacionados à história das instituições educacionais e da cultura escolar. Desse modo, o estudo das práticas educativas desenvolvidas em regimes de clandestinidade apresenta-se como uma importante contribuição ao campo.

\section{REFERÊNCIAS}

ALMEIDA, Maria Salete Bortholazzi. Educação não-formal, informal e formal do conhecimento científico nos diferentes espaços de ensino-aprendizagem. In: Cadernos PDE. Os desafios da escola pública paranaense na perspectiva do professor PDE. Curitiba: Secretaria Estadual de Educação, 2014. v. 2. Disponível em: http://www.diaadiaeducacao. pr.gov.br/portals/cadernospde/pdebusca/producoes_pde/2014/2014_uel_bio_pdp_maria_ salete_bortholazzi_almeida.pdf. Acesso em: 11 abr. 2020.

ALMOND, Gabriel; VERBA, Sidney. The Civic Culture. Political atitudes and democracy in five nations. Princeton: Princeton University Press, 1963.

BAILYN, Bernard. As origens ideológicas da Revolução Americana. Bauru: Editora da Universidade do Sagrado Coração, 2003.

BERSTEIN, Serge. A cultura política. In: RIOUX, Jean Pierre; SIRINELLI, Jean François (org.). Para uma história cultural. Lisboa: Estampa, 1998. p. 349-364. 
BRAGGIO, Ana Karine; FIUZA, Alexandre Felipe. Acervo da DOPS/PR: uma possibilidade de fonte diferenciada para a história da educação. Revista Tempo e Argumento, Florianópolis, v. 5, n. 10, p. 430-452, jul./dez. 2013. Disponível em: https://revistas.udesc. br/index.php/tempo/article/view/2175180305102013430. Acesso em: 5 ago. 2021.

BRANDÃO, Carlos. O que é educação? São Paulo: Brasiliense, 2002.

CABANAS, José María. Teoria da Educação. Concepção antinómica da educação. Lisboa: ASA, 2002.

CATANI, Denice Bárbara; FARIA FILHO, Luciano Mendes de. Um lugar de produção e a produção de um lugar: a história e a historiografia divulgadas no GT História da Educação da ANPEd (1985-2000). Revista Brasileira de Educação, Rio de Janeiro, n. 19, p. 113-172, jan./abr. 2002. Disponível em: https:/www.scielo.br/j/rbedu/a/gh7nGV YpKmBgjShVFSSB8Bv/?lang=PT. Acesso em: 6 ago. 2021.

DUBET, François. Discriminação: a passageira clandestina da pedagogia. In: SILVEIRA, Éder da Silva Silveira; MORETTI, Cheron Zanini; PEREIRA, Marcos Villela (org.). Educação clandestina. Educação e clandestinidade. Porto Alegre: Editora da PUCRS, 2019. v. 1, p. 17-28. Disponível em: https://editora.pucrs.br/livro/1275/ Acesso em: 11 abr. 2020 .

FREITAG, Bárbara. Escola, estado e sociedade. São Paulo: Livraria Editora, 1986.

GOHN, Maria da Glória. Educação não-formal na pedagogia social. CONGRESSO INTERNACIONAL DE PEDAGOGIA SOCIAL, 1., 2006, São Paulo. Anais [...]. São Paulo: Universidade de São Paulo, 2006. Disponível em: http://www.proceedings.scielo. br/scielo.php?pid=MSC0000000092006000100034\&script=sci_arttext. Acesso em: 11 abr. 2020.

KUSCHNIR, Karina; CARNEIRO, Leandro Piquet. As dimensões subjetivas da política: cultura política e antropologia da política. Estudos Históricos, Rio de Janeiro, v. 24, p. 227-250, 1999. Disponível em: http://bibliotecadigital.fgv.br/ojs/index.php/reh/article/ view/2100/1239. Acesso em: 14 abr. 2020

LACERDA FILHO, Mozart. A experiência da clandestinidade política: relatos orais de ex-militantes de esquerda durante a ditadura militar (1964-1979). 2011. Tese (Doutorado em História) - Faculdade de Ciências Humanas e Sociais. Universidade Estadual Paulista em Franca, Franca, 2011.

MORETTI, Cheron Zanini. Exílio. In: STRECK, Danilo Romeu; REDIN, Euclides; ZITKOSKI, Jaime José (org.). Dicionário Paulo Freire. 2. ed. Belo Horizonte: Autêntica, 2010. p. 141-144.

MORETTI, Cheron Zanini. Clandestinidade e insurgência: a experiência educativa descolonial dos/das zapatistas. In: SILVEIRA, Éder da Silva; MORETTI, Cheron Zanini; PEREIRA, Marcos Villela (org.). Educação clandestina. Educação e clandestinidade. Porto Alegre: Editora da PUCRS, 2019a. v. 1, p. 175-202. Disponível em: https://editora. pucrs.br/livro/1275/. Acesso em: 11 abr. 2020. 
MORETTI, Cheron Zanini; PITANO, Sandro de Castro; SCHULZ, Ângela Cristine. Os círculos de cultura e o exílio de Paulo Freire: educação e clandestinidade. In: SILVEIRA, Éder da Silva; MORETTI, Cheron Zanini; PEREIRA, Marcos Villela (org.). Educação Clandestina. Educação e Culturas políticas. Porto Alegre: Editora da PUCRS, 2019b. v. 2, p. 195-216. Disponível em: https://editora.pucrs.br/livro/1276/. Acesso em: 11 abr. 2020.

MOTTA, Rodrigo Patto Sá. A cultura política comunista. In: NAPOLITANO, Marcos; CZAJKA, Rodrigo; MOTTA, Rodrigo Patto Sá (org.). Comunistas brasileiros: cultura política e produção cultural. Belo Horizonte: Editora da UFMG, 2013. p. 15-38.

MOTTA, Rodrigo Patto Sá. Desafios e possibilidades na apropriação de cultura política pela historiografia. In: MOTTA, Rodrigo Patto Sá. Culturas Políticas na História. 2. ed. Belo Horizonte: Fino Traço, 2014. p. 13-38. (Novos Estudos).

NÓVOA, António. Apresentação. In: STEPHANOU, Maria; BASTOS, Maria Helena Camara (org.). Histórias e memórias da educação no Brasil-Século XX. 4. ed. Petrópolis, RJ: Vozes, 2011. v. 3 p. 9-13.

OLIVEIRA, Amanda Assis de; SILVEIRA, Éder da Silva. Educação e clandestinidade: memórias de comunistas brasileiros na União Soviética (1953-1955). Temporalidades, Belo Horizonte, v. 9, n. 2, p. 12-31, maio/ago. 2017. Disponível em: https://periodicos. ufmg.br/index.php/temporalidades/article/view/5909. Acesso em: 14 abr. 2020.

RAMOS, Marise Nogueira. Introdução. In: PENNA, Fernando; QUEIROZ, Felipe; FRIGOTTO, Gaudêncio (org.). Educação democrática. Antídoto ao Escola sem Partido. Rio de Janeiro: UERJ: LPP, 2018. p. 7-13.

RIO DE JANEIRO (Estado). Assembleia Legislativa. Projeto de Lei n. 2974/2014. Cria, no âmbito do sistema de ensino do Estado do Rio de Janeiro, o "Programa Escola sem Partido". Rio de Janeiro: Assembleia Legislativa, 13 maio 2014. Disponível em: http:// alerjln1.alerj.rj.gov.br/scpro1115.nsf/e4bb858a5b3d42e383256cee006ab66a/45741a7e 2ccdc50a83257c980062a2c2. Acesso em: 14 abr. 2020.

RIO DE JANEIRO (Município). Câmara Municipal. Projeto de Lei n. 867/2014. Cria, no âmbito do sistema de ensino do município, o "Programa Escola sem Partido". Rio de Janeiro: Câmara Municipal, 20 jun. 2014. Disponível em: http://mail.camara.rj.gov. br/APL/Legislativos/scpro1316.nsf/f6d54a9bf09ac233032579de006bfef6/5573ae9616 60b4cd83257ceb006bc7d4. Acesso em: 14 abr. 2020.

SCARPELLI, Carolina Dellamore Batista. Marcas da clandestinidade: memórias da ditadura militar brasileira. 2009. Dissertação (Mestrado em Memória Social) - Programa de Pós-graduação em Memória Social. Universidade do Estado do Rio de Janeiro, Rio de Janeiro, 2009.

SEFFNER, Fernando. Não há dois sem três: regimes de clandestinidade e processos educativos. In: SILVEIRA, Éder da Silva Silveira; MORETTI, Cheron Zanini; PEREIRA, Marcos Villela (org.). Educação clandestina. Educação e clandestinidade. Porto Alegre: Editora da PUCRS, 2019. v. 1, p. 37-56. Disponível em: https://editora.pucrs.br/ livro/1275/. Acesso em: 11 abr. 2020. 
SILVEIRA, Éder da Silva; MORETTI, Cheron Zanini; VILARRUEL, Antonio. Memórias de uma Educação Clandestina: a formação de quadros revolucionários comunistas brasileiros na antiga União Soviética. In: ANPED SUL, 11., 2016, Curitiba. Anais eletrônicos [...]. Curitiba: UFPR, 2016. Disponível em: http://www.anpedsul2016.ufpr.br/ wp-content/upload/2015/11/Eixo-1_\%C3\%89DER-DA-SILVA-SILVEIRA-CHERONZANINI-MORETTI-ANTONIO-VILLARRUEL.pdf. Acesso em: 11 abr. 2020.

SILVEIRA, Éder da Silva; MORETTI, Cheron Zanini. Memórias de uma educação clandestina: comunistas brasileiros e escolas políticas na União Soviética na década de 1950. Educar em Revista, Curitiba, v. 33, n. 66, p. 193-208, out./dez. 2017. Disponível em: http://www.scielo.br/pdf/er/n66/0104-4060-er-66-193.pdf. Acesso em: 11 abr. 2020.

SILVEIRA, Éder da Silva; MORETTI, Cheron Zanini; PEREIRA, Marcos Villela (org.). Educação Clandestina. Educação e clandestinidade. Porto Alegre: Editora da PUCRS, 2019a. v. 1. Disponível em: https://editora.pucrs.br/livro/1275/. Acesso em: 14 abr. 2020.

SILVEIRA, Éder da Silva; MORETTI, Cheron Zanini; PEREIRA, Marcos Villela (org.). Educação Clandestina. Educação e Culturas políticas. Porto Alegre: Editora da PUCRS, 2019b. v. 2. Disponível em: https://editora.pucrs.br/livro/1276/. Acesso em: 14 abr. 2020.

SILVEIRA, Éder da Silva et al. Educação Comunista nas páginas do jornal A Classe Operária (1968-1970). In: SILVEIRA, Éder da Silva; MORETTI, Cheron Zanini; PEREIRA, Marcos Villela (org.). Educação Clandestina. Educação e Culturas políticas. Porto Alegre: Editora da PUCRS, 2019c. v. 2. Disponível em: https://editora.pucrs.br/ livro/1276/. Acesso em: 14 abr. 2020.

WEBER, Douglas; DARSIE, Camilo. Vidas Clandestinas: espacialidades que educam/ produzem sujeitos migrantes. In: SILVEIRA, Éder da Silva; MORETTI, Cheron Zanini; PEREIRA, Marcos Villela (org.). Educação clandestina. Educação e clandestinidade. Porto Alegre: Editora da PUCRS, 2019. v. 1, p.115-128. Disponível em: https://editora. pucrs.br/livro/1275/. Acesso em: 11 abr. 2020.

Texto recebido em 16/07/2020.

Texto aprovado em 17/06/2021. 